\title{
Reactogenicity and immunogenicity of a surface-antigen-adsorbed influenza virus vaccine in children
}

\author{
LOUISE M. EASTWOOD ${ }^{1}$, R. JENNINGS ${ }^{2}$, R. D. G. MILNER ${ }^{1}$, \\ AND C. W. POTTER ${ }^{2}$ \\ From the ${ }^{1}$ Department of Paediatrics, Children's Hospital, Western Bank, Sheffield S10 2TH and the \\ ${ }^{2}$ Department of Virology, Academic Division of Pathology, University of Sheffield, Beech Hill Road, \\ Sheffield S10 2RX, UK
}

SUMMARY An influenza virus vaccine containing the purified surface haemagglutinin and neuraminidase antigens of $\mathrm{A} /$ Victoria/75 and $\mathrm{B} / \mathrm{Hong} \mathrm{Kong} / 73$ viruses adsorbed to an aluminium hydroxide gel was assessed for reactogenicity and immunogenicity in children aged 4 to 11 years, since there is no influenza virus vaccine available for this age group. Significant serum haemagglutination-inhibiting antibody responses to the $\mathrm{A} / \mathrm{Victoria} / 75$ and $\mathrm{B} / \mathrm{Hong} \mathrm{Kong} / 73$ haemagglutinin antigens present in the vaccine were observed in $47 \%$ and $35 \%$, respectively, of the children vaccinated, with a single dose. The vaccine induced no significant local or systemic reactions.

Although the routine immunisation of children against influenza is not obligatory, influenza $\mathbf{A}$ viruses are an important cause of illness in infants and young children (Fox and Kilbourne, 1973) and can cause serious morbidity and even death in children of any age with chronic heart, respiratory, and other underlying disease (Phillips et al., 1973; Glezen, 1977). Unfortunately, conventional, inactivated whole influenza virus vaccines are reactogenic in infants and young children (Marine and Stuart-Harris, 1976; Wright et al., 1976), and this has prohibited their use in this cohort of the population. Studies comparing whole, inactivated influenza virus vaccines with split or the more highly purified subunit influenza virus vaccines in adults have shown the latter to be less reactogenic (Brandon et al., 1967; Barry et al., 1976). It is, therefore, considered possible that these vaccines may be more acceptable for children.

In the present study, an assessment of the reactogenicity and immunogenicity of a bivalent influenza virus vaccine containing only the haemagglutinin and neuraminidase surface antigens of $A / V i c t o r i a / 75$ and B/Hong Kong/73 influenza viruses was carried out in young children. The surface antigens of these

Received for publication 29 November 1978 viruses were adsorbed to aluminium hydroxide gel. A similar, surface-antigen-adsorbed vaccine has been shown to induce few reactions and good serum antibody responses in adults (Potter et al., 1975, 1977).

\section{Material and methods}

VACCINE

The adsorbed, surface-antigen influenza virus vaccine, Fluvirin, manufactured by Evans Biologicals for Duncan Flockhart Ltd, was used in the present study. The vaccine was prepared from egg-grown virus and purified by zonal centrifugation; the surface antigens of the intact virus particle, the haemagglutinin (HA) and neuraminidase $(\mathrm{N})$, were separated from unwanted core material by centrifugation through a sucrose gradient containing Triton N 101 and then adsorbed on to an aluminium hydroxide gel (Brady and Furminger, 1976). Before adsorption on to the gel, rocket immunoelectrophoresis (Oxford and Schild, 1978), carried out at the National Institute of Biological Standards and Control, showed that the vaccine contained $8.4 \mu \mathrm{g} \mathrm{HA}$ of $\mathrm{A} /$ Victoria/3/75 (H3N2) and 12.7 $\mu \mathrm{g} \mathrm{HA}$ of B/Hong Kong/8/73 per dose; $10 \mu \mathrm{g}$ HA is approximately equivalent to 200 international units (IU). When the HA concentration of the virus was tested after adsorption to aluminium hydroxide gel and just before inoculation, the 
vaccine was found to contain only $2.9 \mu \mathrm{g} \mathrm{HA}$ of A/Victoria/3/75 and $2.0 \mu \mathrm{g}$ HA of B/Hong $\mathrm{Kong} / 8 / 73$ per dose. However, these latter figures may be low since some of the HA antigen has probably remained attached to the gel, and antigen thus bound would be unmeasurable by rocket immunoelectrophoresis.

\section{STUDY GROUP}

Children from 2 to 11 (median 7) years of age attending the outpatient clinic at the Children's Hospital, Sheffield were recruited after written consent had been obtained from informed parents. Only one child was under 4 years, and only three were over 9 years of age. Children with a history of convulsions or allergy to eggs, and those receiving immunosuppressive or corticosteroid therapy, were excluded. Altogether 49 children completed the study, including 13 asthmatics, seven diabetics, and one child with cystic fibrosis. The remainder were healthy children who were mainly siblings of patients attending the hospital. Each child received a single, $0.5 \mathrm{ml}$, dose of vaccine by the intramuscular route immediately after collection of a venous blood sample. Three days after immunisation the parents were contacted by telephone and carefully questioned as to the nature of any local or systemic reactions. Four to six weeks later a second blood sample was collected from each child.

\section{SEROLOGICAL STUDIES}

Paired sera were tested for haemagglutinationinhibiting (HI) antibodies using 8 haemagglutinating units of virus and employing the microtitre technique (Sever, 1962).

The sera were pretreated with cholera filtrate to remove non-specific inhibitors and tested for $\mathrm{HI}$ antibodies to the homologous $\mathrm{A} /$ Victoria/75 and B/Hong Kong/73 viruses.

Assays for neuraminidase-inhibiting (NI) antibodies were carried out by an automated modification (Bevan et al., 1975) of the standard World Health Organisation methods (Aymard-Henry et al., 1973) using the $X 48$ influenza strain (Hequi 1 N2), a recombinant of $\mathrm{A} / \mathrm{Victoria} / 75$ and $\mathrm{A} /$ Equi/63 viruses, as the source of neuraminidase.
Results

\section{CLINICAL REACTIONS}

The clinical reactions attributable to the vaccine were mild, and the findings are shown in Table 1 . Of 49 children, $18(37 \%)$ developed mild local reactions consisting of slight soreness and aching at the inoculation site at some time during the three days after immunisation. Two of these children also had local swellings, two had redness, and one a bruise at the inoculation site. The incidence of systemic reactions was also low in the present study, and only one child, a 7-year-old diabetic girl, with normally stable diabetes, had a systemic reaction apparently associated with immunisation. This child showed raised levels of sugar and ketones in the urine for two days after immunisation but no other effects. In addition, one boy suffered an asthmatic attack 36 hours after immunisation. Although temperatures were not recorded, there were no reports of fever after immunisation in any of the children.

\section{SERUM ANTIBODY RESPONSES AFTER}

IMMUNISATION

The serum HI antibody responses of the volunteers to the bivalent $\mathrm{A} / \mathrm{Victoria} / 75$ and $\mathrm{B} /$ Hong Kong/73 influenza virus vaccine are shown in Table 2. A total of $23(47 \%)$ of the 49 children responded to immunisation with four-fold rises in serum $\mathrm{HI}$ antibody titre to influenza A/Victoria/75. The geometric mean titre (gmt) of this antibody rose from 17.2 preimmunisation to 67.4 four to six weeks after immunisation, an increase of 3.9-fold. In addition, the number of children with serum $\mathrm{HI}$ antibody levels of $>1: 40$ to $A / V i c t o r i a / 75$ rose from 14 $(29 \%)$ to $29(59 \%)$ after immunisation.

The serum $\mathrm{HI}$ antibody response to the $\mathrm{B} /$ Hong Kong/73 component of the vaccine is also shown in Table 2. Seventeen $(35 \%)$ of the 49 children responded with $>$ 4-fold serum HI antibody increases to this virus, and the gmt rose from 5.9 to $15 \cdot 7$, an increase of $2 \cdot 7$-fold.

The serum NI antibody response of the children to immunisation with the $\mathrm{A} / \mathrm{Victoria} / 75: \mathrm{B} / \mathrm{Hong}$ $\mathrm{Kong} / 73$ influenza virus vaccine is also presented in Table 2. Owing to the small volume of serum avail-

Table 1 Incidence of clinical reactions in children after immunisation with influenza A/Victoria/3/75:B/Hong Kong/8/73 surface-antigen-adsorbed vaccine

\begin{tabular}{|c|c|c|c|c|c|c|c|}
\hline \multirow[t]{2}{*}{$\begin{array}{l}\text { No. of } \\
\text { children }\end{array}$} & \multicolumn{3}{|c|}{ No. $(\%)$ with local reactions lasting: } & \multicolumn{2}{|c|}{$\begin{array}{l}\text { Total with local } \\
\text { reactions }\end{array}$} & \multicolumn{2}{|c|}{ Systemic reactions } \\
\hline & 1 day & 2 days & 3-5 days & No. & $\%$ & No. & $\%$ \\
\hline 49 & $5(10 \cdot 20)$ & $9(18 \cdot 37)$ & $4(8 \cdot 16)$ & 18 & $36 \cdot 73$ & 1 & 2.04 \\
\hline
\end{tabular}


Table 2 Serum HI and NI antibody responses of children after immunisation with bivalent surface-antigen-adsorbed influenza virus vaccine

\begin{tabular}{|c|c|c|c|c|}
\hline & \multicolumn{2}{|c|}{ Response to A/Victoria/75 } & \multicolumn{2}{|c|}{ Response to B/Hong Kong/73 } \\
\hline & HI antibodies & NI antibodies & HI antibodies & NI antibodies \\
\hline \multirow{5}{*}{$\begin{array}{l}\text { No. of serum pairs tested } \\
\text { No. }(\%) \text { with }>4 \text {-fold antibody increase post- } \\
\text { immunisation } \\
\text { No. (\%) with titres }<1: 10 \text { before and after immunisation } \\
\text { No. }(\%) \text { with titres }>1: 40 \text { before and after immunisation } \\
\text { GMT of antibody before and after immunisation } \\
\text { (fold increase) }\end{array}$} & 49 & 31 & 49 & 38 \\
\hline & $23(4$ & $10(32)$ & $17(35)$ & $17(45)$ \\
\hline & $19(39)-3(6)$ & $15(48)-6(19)$ & $42(86)-22(45)$ & $36(95)-16(42)$ \\
\hline & $14(29)-29(59)$ & $3(10)-15(48)$ & $0(-)-16(33)$ & $0(-)-18(47)$ \\
\hline & $17 \cdot 2-67 \cdot 4(3.9)$ & $13 \cdot 5-30 \cdot 5(2 \cdot 3)$ & $5.9-15 \cdot 7(2 \cdot 7)$ & $2 \cdot 5-17 \cdot 9(7 \cdot 1)$ \\
\hline
\end{tabular}

able in some of the specimens, sera from all the children who took part in the study were not tested, but the results do show that $10(32 \%)$ of the 31 volunteers tested responded with $>4$-fold serum NI antibody increases to A/Victoria/75 after immunisation. In addition, $17(45 \%)$ of the 38 children whose sera were tested for B/Hong Kong/73 NI antibody showed evidence of significant antibody rises to the neuraminidase antigen of this virus.

\section{Discussion}

Several workers have reported adverse local and systemic reactions after the use of conventional, inactivated, whole virus vaccines in children (Parkman et al., 1976; Wright et al., 1976; Schevill and Marks, 1977) and particularly in infants (Marine and Stuart-Harris, 1976; Wright et al., 1976). The present results suggest that the A/Victoria/75:B/Hong Kong/73 surface-antigenadsorbed vaccine used in the present study is both safe and acceptable in children aged 4 years or older. The local systemic reactions after vaccine administrations were mild, and this is in accordance with the findings in adults receiving surface-antigen-adsorbed vaccine (Potter et al., 1977). This may well apply generally to subunit and split influenza virus vaccines (Davenport et al., 1964; Phillips et al., 1973). Recent studies in both infants and children (Gross et al., 1977) showed that a split-product A/Port Chalmers/ $73: B / H o n g$ Kong/73 influenza virus vaccine produced markedly fewer systemic reactions than a conventional whole virus vaccine given at an equivalent dose. The present studies did not extend to infants, and the reactogenicity of surface-antigenadsorbed vaccine in this group has yet to be determined.

The serological response of adults to surfaceantigen-adsorbed influenza virus vaccine was found to be good (Potter et al., 1977) but the results reported here suggest that the response of children may be lower. Only $47 \%$ of the children receiving immunisation showed significant $\mathrm{HI}$ antibody increases to the A/Victoria/75 component of the vaccine, and only $35 \%$ responded similarly to the B/Hong Kong/73 component. However, the percentage of children with serum $\mathrm{HI}$ antibody titres to influenza $A / V i c t o r i a / 75$ of $>1: 40$, the postulated protective level against homologous virus infection (Hobson et al., 1972), increased from 29 to 59 after immunisation. Other workers have shown that children respond less well than adults to subunit or split influenza vaccines (Parkman et al., 1976), and young persons unprimed with the swine influenza virus respond poorly to split $\mathrm{A} / \mathrm{New}$ Jersey/76 virus vaccine (Gross and Ennis, 1977). The influenza B/Hong Kong/73 component of split virus vaccine has been shown to be a poor immunogen in children under 10 years of age (Gross et al., 1977), and the results of the present study are in agreement with these findings.

The poor response of children is almost certainly due to their relative lack of prior exposure to influenza viruses, and this view is supported by the similarly poor response of young adults even to whole virus vaccines containing antigens to which they were unprimed. For this reason it seems probable that a second, booster dose of subunit influenza vaccine will be required to afford adequate protection in a population which has not experienced the relevant influenza virus strains.

The serological response of children in the present study to the A/Victoria/75 and B/Hong Kong/73 neuraminidase antigens was similar to that seen for the HA antigens, and less than half of the subjects tested showed significant serum NI antibody responses. However, the gmt of serum NI antibody was increased in the group as a whole, and high levels of this antibody may contribute to protection against influenza (Monto and Kendal, 1973).

In conclusion, these studies show that the surfaceantigen-adsorbed vaccine used is of low reactogenicity in children 4 to 11 years of age and induces significant serum $\mathrm{HI}$ and NI antibody responses. 
We thank Evans Biologicals Ltd for their provision of the influenza virus vaccine used in this study, and Miss A. M. Bevan, of Evans Biologicals Ltd, for carrying out the assays for neuraminidase-inhibiting antibody. We also thank the volunteers who took part, and Mrs T. Smith and Miss J. Hawley for excellent technical assistance.

\section{References}

Aymard-Henry, M., Coleman, M. T., Dowdle, W. R., Laver, W. G., Schild, G. C., and Webster, R. G. (1973). Influenzavirus neuraminidase and neuraminidaseinhibition test procedures. Bulletin of the World Health Organisation, 48, 199-202.

Barry, D. W., Mayner, R. E., Hockstein, H. D., Dunlap, R. C., Rastogi, S. C., Hannah, J. E., Blackburn, R. J., Sullivan, J. L., and Gerety, R. J. (1976). Comparative trial of influenza vaccines. II. Adverse reaction in children and adults. American Journal of Epidemiology, 104, 47-59.

Bevan, A. M., Furminger, I. G. S., and Smith, C. H. (1975). Neuraminidase assay of influenza vaccines. Developments in Biological Standardisation, 18, 173-180.

Brady, M. I., and Furminger, I. G. S. (1976). A surface antigen influenza vaccine. 1. Purification of haemagglutinin and neuraminidase proteins. Journal of Hygiene, 77, 161-172.

Brandon, F. B., Barrett, C. D., Jr., Hook, A. E., and Lease, G. O. (1967). Human febrile response to influenza virus or its ether isolated hemagglutinins. Proceedings of the Society for Experimental Biology and Medicine, 125, 683-686.

Davenport, F. M., Hennessy, A. V., Brandon, F. M., Webster, R. G., Barret, C. D., Jr., and Lease, G. O. (1964). Comparisons of serologic and febrile responses in humans to vaccination with influenza $A$ viruses and their hemagglutinins. Journal of Laboratory and Clinical Medicine, 63, 5-13.

Fox, J., and Kilbourne, E. D. (1973). Epidemiology of influenza. (Summary of influenza workshop IV.) Journal of Infectious Diseases, 128, 361-386.

Glezen, W. P. (1977). Influenza prophylaxis for children. American Journal of Diseases in Children, 131, 628-630.

Gross, P. A., and Ennis, F. A. (1977). Influenza vaccine: split-product versus whole-virus types-how do they differ? New England Journal of Medicine, 296, 567-568.

Gross, P. A., Ennis, F. A., Gaerlan, P. F., Denson, L. J., Denning, C. R., and Schiffman, D. (1977). A controlled, double-blind comparison of reactogenicity, immunogenicity, and protective efficacy of whole-virus and split-product influenza vaccines in children. Journal of Infectious Diseases, 136, 623-632.

Hobson, D., Curry, R. L., Beare, A. S., and WardGardner, A. (1972). The role of serum haemagglutination-inhibiting antibody in protection against challenge infection with influenza A2 and B viruses. Journal of Hygiene, 70, 767-777.

Marine, W. M., and Stuart-Harris, C. (1976). Reactions and serologic responses in young children and infants after administration of inactivated monovalent influenza A vaccine. Journal of Paediatrics, 88, 26-30.

Monto, A. S., and Kendal, A. P. (1973). Effects of neuraminidase antibody on Hong Kong influenza. Lancet, 1, 623-625.

Oxford, J. S., and Schild, G. C. (1978). Quantitation of influenza virus structural proteins using rocket immuno-electrophoresis. Journal of General Virology, 38, 187-193.

Parkman, P. D., Galasso, G. J., Top, F. H., Jr., and Noble, G. R. (1976). Summary of clinical trials of influenza vaccines. Journal of Infectious Diseases, 134, 100-107.

Phillips, C. F., Phillips, C. A., Hodgkin, W. E., Forsyth, B. R., Rubin, B. A., and Geraghty, M. E. (1973). Killed subunit influenza vaccine in children. Paediatrics, 52, 416-419.

Potter, C. W., Jennings, R., McLaren, C., Edey, D., and Stuart-Harris, C. H. (1975). A new surface-antigenadsorbed-influenza virus vaccine. II. Studies in a volunteer group. Journal of Hygiene, 75, 353-362.

Potter, C. W., Jennings, R., Phair, J. P., Clark, A., and Stuart-Harris, C. H. (1977). Dose-response relationship after immunization of volunteers with a new, surfaceantigen-adsorbed influenza virus vaccine. Journal of Infectious Diseases, 135, 423-431.

Schevill, S., and Marks, M. I. (1977). Adverse reactions to 1975 bivalent influenza vaccine in children. Journal of the Canadian Medical Association, 116, 271-272.

Sever, J. L. (1962). Application of a microtechnique to viral serological investigations. Journal of Immunology, 88, 320-329.

Wright, P. F., Sell, S. H. W., Thompson, J., and Karzon, D. T. (1976). Clinical reactions and serologic response following inactivated, monovalent influenza type $B$ vaccine in young children and infants. Journal of Paediatrics, 88, 31-35.

Requests for reprints to: Dr R. Jennings, Department of Virology, Academic Division of Pathology, University of Sheffield Medical School, Beech Hill Road, Sheffield S10 2RX, UK. 